Conclusion: Hip involvement is a major and highly prevalent issue in our JIA patients.

Disclosure of Interests: None declared

DOI: 10.1136/annrheumdis-2021-eular.2619

\section{AB0731 CERVICAL SPINE INVOLVEMENT IN PATIENTS WITH JUVENILE IDIOPATHIC ARTHRITIS}

S. Bouden ${ }^{1}$, N. Ben Chekaya ${ }^{1}$, A. Ben Tekaya ${ }^{1}$, O. Saidane ${ }^{1}$, R. Tekaya ${ }^{1}$, I. Mahmoud ${ }^{1,1}$, L. Abdelmoula ${ }^{1}{ }^{1}$ Charles Nicolle Hospital, Rheumatology, Tunis, Tunisia

Background: Juvenile idiopathic arthritis (JIA) is the most common chronic rheumatic disease in children. In contrast to adult rheumatoid arthritis, where numerous studies have shown a high prevalence of involvement of the cervical spine, few studies have been published examining this entity in JIA.

Objectives: We aimed to analyze clinical and radiological findings of cervica spine involvement in patients with JIA.

Methods: A retrospective study including 35 patients was conducted between 2010 and 2019. The patients enrolled met the ILAR criteria for the diagnosis of JIA. Clinical, biological, and radiological data were collected. Patients had a radiological evaluation that included cervical spine $\mathrm{x}$-rays in antero-posterior, lateral and lateral views with flexion.

Results: Thirty-five patients were enrolled. The mean age of the disease onset was 9 years [3-15]. The mean age of the patients at the time of the study was 37.8 years [17-69]. The mean duration of the disease was 27 years [2-56]. These patients were assigned to discrete JIA categories: rheumatoid factor positive polyarthritis $(43.5 \%)$, rheumatoid factor negative polyarthritis $(21.7 \%)$, enthesitis-related arthritis (17.4\%), oligoarthritis (13\%) and psoriatic arthritis $(4.4 \%)$. Sixteen patients $(45 \%)$ reported neck pain. Cervical spine involvement occurred on average 7 years [0-13] after the JIA onset. Cervical spine radiographs showed anterior atlantoaxial subluxation $(>5 \mathrm{~mm})$ in 8 patients. Magnetic-resonance imagining was performed in 9 patients that had abnormal neurological examination showing a pannus formation of $\mathrm{C} 1-\mathrm{C} 2$ junction (3 cases), a basilar invagination (4 cases) and erosions of the odontoid process ( 2 cases). A cervical collar has been used for immobilization in patients with significant cervical spine damage. A C1-C2 arthrodesis was proposed to 4 patients.

Conclusion: These findings suggest that the presence of cervical involvement in JIA patients is frequent. Radiologic assessment of cervical spine should be systematically performed for early detection and to prevent its complications. Disclosure of Interests: None declared

DOI: 10.1136/annrheumdis-2021-eular.2648

\section{AB0732 JUVENILE IDIOPATHIC ARTHRITIS IN ADULTHOOD}

N. Ben Chekaya ${ }^{1}$, S. Bouden ${ }^{1}$, A. Ben Tekaya ${ }^{1}$, O. Ben Saidane ${ }^{1}$, R. Tekaya ${ }^{1}$, I. Mahmoud', L. Abdelmoula ${ }^{1} .{ }^{1}$ Charles Nicolle Hospital, Rheumatology, Tunis, Tunisia

Background: Juvenile idiopathic arthritis (JIA) is the most common chronic rheumatic disease of unknown aetiology in childhood. Approximately $40-60 \%$ of patients with juvenile idiopathic arthritis (JIA) have continuous or recurrent disease activity extending into adulthood.

Objectives: The aim of this study was to evaluate the clinical, biological and radiological course of JIA in adulthood.

Methods: A retrospective study including 35 patients was conducted between 2010 and 2019. The patients enrolled met the ILAR criteria for the diagnosis of JIA. Patients with JIA older than 20 years were included. Data regarding sociodemographic features, Physical growth, disease activity, biological and radiological parameters were analysed.

Results: Thirty one patients were recruited. The sex ratio was 0.53 . The mean age at the time of the study was 38.9 years [20-69]. The mean age of the disease onset was 9 years [3-16]. These patients were assigned to discrete JIA categories: rheumatoid factor positive polyarthritis (47.7\%), rheumatoid factor negative polyarthritis $(23.9 \%)$, oligoarthritis $(14.2 \%)$, enthesitis-related arthritis $(9.5 \%)$, and psoriatic arthritis (4.7\%).A failure to thrive was seen in $33.3 \%$ of patients. Overweight and obesity were found in $38 \%$ and $19 \%$ of patients, respectively. Biological inflammatory syndrome was noted in $52 \%$ of patients, and $65.2 \%$ had active disease. Hip involvement was noted in $43.5 \%$ of patients and $17.4 \%$ of them had a total hip replacement. Sixteen patients had neck pain and the imagining showed an atloid-axoid dislocation in $50 \%$ of them. Radiographs showed a joint destruction in $60.9 \%$ of patients and a wrist arthritis was the most frequent involvement.

Conclusion: Most of our included patients maintain active disease and have functional impairment in adulthood.

Disclosure of Interests: None declared

DOI: 10.1136/annrheumdis-2021-eular.2658

\section{$\mathrm{AB} 0733$ \\ DADA2 VASCULITIS PRESENTING AS POSTERIOR REVERSIBLE ENCEPHALOPATHY SYNDROME (PRES): AN ATYPICAL PRESENTATION}

M. Mamadapur ${ }^{1}$, S. Mahadevan ${ }^{1}$, A. Singh ${ }^{1}$, R. Chakravarthy C H2, R. S2,

T. T N2. 'Madras Medical College, Clinical Immunology and Rheumatology,

Chennai, India; ${ }^{1}$ Madras Medical College, Clinical Immunology and

Rheumatology, Chennai, India

Background: Deficiency of Adenosine Aminase deficiency 2 is monogenic dis ease presenting with multisystem involvement of vasculitis, Stroke ${ }^{1}$, hematological manifestations. We hereby present a young child who presented with PRES initially and later diagnosed as DADA2.Only one case of DADA2 presenting as PRES is reported so $\operatorname{far}^{2}$. This case highlights the atypical presentation of DADA2.

Objectives: A case report to highlight the rare presentation of DADA2 vasculits. Methods: 8 year old developmentally normal male child,born out of consanguineous marriage presented with with fever,abdominal pain, seizures 1 year back Ultrasound of abdomen revelaed mesenteric lymphadenitis and MRI Brain was suggestive of Meningoencephalitis. He was managed with antivirals and antibiotics then.

6 months later, he had fever,skin rash,pain abdomen,status epilepticus, hypertension followed by gangrene of fingers and toes.APLA,ANA,ANCA workup was negative. Complete Hemogram was normal. CRP was $130 \mathrm{mg} / \mathrm{dl}$. CT Abdomen was normal and no evidence of aneurysms. Renal Doppler Ultrasound was normal.CT upper limb showed left radial and ulnar artery significant narrowing with patchy occlusion. MRI Brain showed bilateral fronto parietal,occipital,putamen,left insula and subcortical and cortical T2W FLAIR hyperintensity without diffusion restriction suggestive of PRES. He was diagnosed as Childhood Polyarteritis Nodosa and treated with cyclophosphamide. Genetic Analysis of ADA2(CECR1) gene mutation by Sanger Sequencing of exons 2 to 10 showed a known variant (rs202134424) in ADA2 gene.

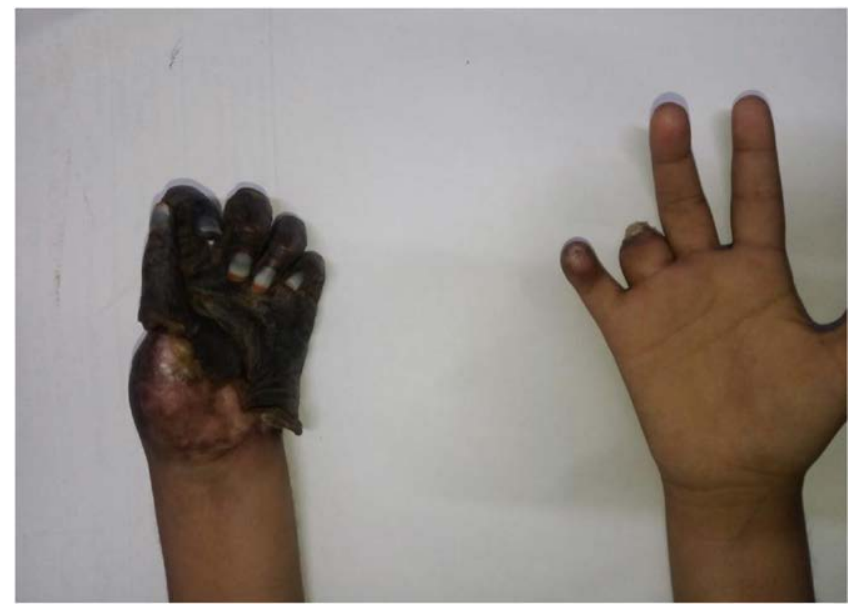

Figure 1. Gangrene of left $1-5^{\text {th }}$ digits and right $4^{\text {th }}$ and $5^{\text {th }}$ digit resorption

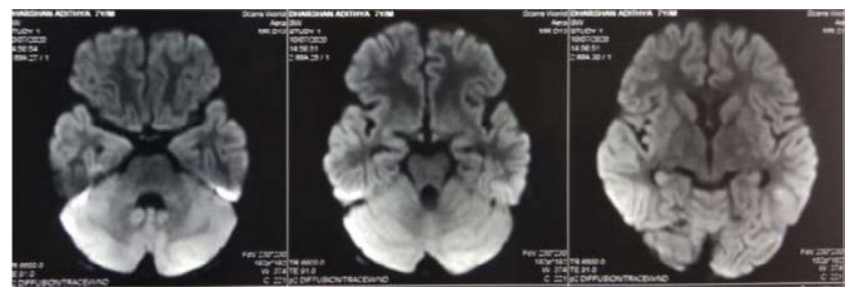

Figure 2. T2W FLAIR image showing bilateral fronto parietal,occipital,putamen, left insula and subcortical and cortical hyperintensity without diffusion restriction suggestive of PRES.

Results: He was started on Infliximab and is on follow up. No further events noted so far.Rehabilitation of left upper hand was done.

Conclusion: DADA2 can present with varied CNS manifestations like infarct,hemorrhage, aneurysms and PRES. High index of suspicion and early recognition can help in maintaining vascular integrity.

\section{REFERENCES:}

[1] Ganhão S, Loureiro G, Oliveira D, dos-Reis-Maia R, Aguiar F, Quental R et al. Two cases of ADA2 deficiency presenting as childhood polyarteritis 
nodosa: novel ADA2 variant, atypical CNS manifestations, and literature review. Clinical Rheumatology. 2020;39(12):3853-3860.

[2] Sharma A, Naidu G, Sharma V, Jha S, Dhooria A, Dhir V et al. Deficiency of Adenosine Deaminase 2 in Adults and Children: Experience From India. Arthritis \& Rheumatology. 2020;73(2):276-285.

Disclosure of Interests: None declared

DOI: 10.1136/annrheumdis-2021-eular.2660

\section{$\mathrm{AB} 0734$ \\ REMISSION IN JUVENILE IDIOPATHIC ARTHRITIS AFTER WITHDRAWAL OF SYSTEMIC TREATMENT}

L. C. Charca Benavente ${ }^{1}$, L. Trives Folguera ${ }^{2}$, L. R. Caballero Motta ${ }^{2}$, A. M. Anzola Alfaro ${ }^{2}$, K. López Gloria ${ }^{2}$, J. M. Alvaro Gracia ${ }^{2}$, I. Monteagudo², J. C. Nieto González ${ }^{2}{ }^{1}$ Hospital Universitario Central de Asturias, Rheumatology, Oviedo, Spain; ${ }^{2}$ Gregorio Marañón Hospital, Pediatric Rheumatology, Madrid, Spain

Background: Juvenile idiopathic arthritis (JIA) requires frequent systemic treatments, the ideal goal being to achieve remission. Questions remain as to when treatment can be stopped and how to balance the risks and benefits of continuing medications against the possibility of a flare after discontinuation. There is currently little conclusive evidence on the management of JIA in remission.

Objectives: To determine the time to remission and frequency of flares in patients with JIA after withdrawal of systemic treatment in a single-centre cohort. Methods: Patients with JIA visited in the last 15 years were included. A retrospective cross-sectional study was performed. Demographic data such as sex, age at diagnosis, current age, subcategories of JIA were collected. Systemic treatment was also collected (date of discontinuation, date of flare after discontinuation, time in remission, time of treatment until discontinuation, discontinuation of biologic therapy while maintaining methotrexate). For the analysis of qualitative variables, absolute and relative frequencies were used; for quantitative variables, median and IR; for comparative analysis, Chi-square and Mann-Whitney $U$ test.

Results: We included 146 patients with JIA. Demographic data are shown in Table 1. $134(90.4 \%)$ patients required systemic treatment (synthetic and/or biological DMARDs), of which 61 (45.5\%) discontinued treatment completely at some point. Of the total number of patients who discontinued all systemic treatment, $19(31.1 \%)$ had a flare with a median time in remission of 4.1 years (IR 1.3-9.1). 17 of the 134 patients (12.7\%) with systemic treatment discontinued biologic therapy while maintaining methotrexate, of which $12(70.6 \%)$ patients had a flare with a median time in remission of 0.9 years (IR 0.6-1.2). The differences between the frequency of flares and median time in remission between both treatment discontinuation groups (all systemic treatment versus discontinuation of biologic while maintaining methotrexate) were statistically significant $(p<0.001)$. The median time from systemic treatment to complete withdrawal was 3.2 years (IR 1.9-4.8).

Table 1. Demographic characteristics of patients with JIA

\begin{tabular}{lc}
\hline Variables & $\mathrm{N} 146$ \\
\hline Sex: Women n (\%) & $89(60.3)$ \\
Age at onset (years, median (IR)) & $4.6(2.5-9.2)$ \\
Current age (years, median (IR)) & $16.7(11.1-20.9)$ \\
Types of JIA: & $66(45.2)$ \\
Persistent oligoarticular n (\%) & $11(7.5)$ \\
Extended oligoarticular n (\%) & $29(19.9)$ \\
Polyarticular RF - n (\%) & $3(2.1)$ \\
Polyarticular RF + n (\%) & $12(8.2)$ \\
Enthesitis-related n (\%) & $9(6.2)$ \\
Psoriatic $\mathrm{n}(\%)$ & $16(11.0)$ \\
Systemic $\mathrm{n}(\%)$ & \\
\hline
\end{tabular}

Conclusion: One third of the patients in whom all systemic treatment was withdrawn had a flare (70\% remain in remission without medication) with a median time in remission of 4 years. On the other hand, two-thirds of patients in whom biologic therapy was withdrawn while maintaining methotrexate had a flare, with a shorter time in remission. The differences between both groups with withdrawal of systemic treatment are statistically significant $(p<0.001)$.

REFERENCES:

[1] Halyabar O, Mehta J, Ringold S, Rumsey DG, Horton DB. Treatment Withdrawal Following Remission in Juvenile Idiopathic Arthritis: A Systematic Review of the Literature. Paediatr Drugs. 2019 Dec;21(6):469-492. doi: 10.1007/s40272-019-00362-6.

[2] Simonini G, Ferrara G, Pontikaki I, Scoccimarro E, Giani T, Taddio A, Meroni PL, Cimaz R. Flares After Withdrawal of Biologic Therapies in Juvenile Idiopathic Arthritis: Clinical and Laboratory Correlates of Remission
Duration. Arthritis Care Res (Hoboken). 2018 Jul;70(7):1046-1051. doi: 10.1002/acr.23435

[3] Chhabra A, Robinson C, Houghton K, Cabral DA, Morishita K, Tucker LB, Petty RE, Larché M, Batthish M, Guzman J. Long-term outcomes and disease course of children with juvenile idiopathic arthritis in the ReACCh Out cohort: a two-centre experience. Rheumatology (Oxford). 2020 Dec 1;59(12):3727-3730. doi: 10.1093/rheumatology/keaa118.

Disclosure of Interests: None declared

DOI: 10.1136/annrheumdis-2021-eular.2718

\section{AB0735 POLYMORPHISMS OF GENES CD14, C-REACTIVE PROTEIN, FIBRINOGEN BETA CHAIN, ASSOCIATED WITH THE DEVELOPMENT OF KAWASAKI DISEASE AND CORONARY ARTERY ANEURYSMS IN CHILDREN FROM CENTRAL RUSSIA}

M. Kantemirova ${ }^{1}$, S. Kurbanova ${ }^{1}$, Y. Novikova ${ }^{1}$, A. Glazyrina ${ }^{1}$, M. Azova ${ }^{2}$, E. Zheludova ${ }^{2}$, E. Tarasenko ${ }^{2}$, D. Ovsyannikov ${ }^{1} .{ }^{1} R U D N$ University, Department of Pediatrics, Moscow, Russian Federation; ${ }^{2}$ RUDN University, Department of Biology and General Genetics, Moscow, Russian Federation

Background: Kawasaki disease (KD) is a multifactorial disease with a genetic predisposition, systemic vasculitis complicated by the formation of coronary artery aneurysms (CAA). Its pathogenesis is based on immune inflammation with an increase in the concentration of pro-inflammatory cytokines, the level of C-reactive protein (CRP), and coagulation disorder.

Objectives: to search for polymorphisms of genes cluster of differentiation CD14, CRP, fibrinogen beta chain (FGB), associated with the KD development and a predisposition to the CAA formation among patients with KD living in Moscow and the Moscow region.

Methods: genotyping for gene polymorphisms CD14 -159 C>T (rs2569190), CRP 3872 C>T (rs1205), FGB - 455 G>A (rs1800790) by PCR in 31 children 1 month -10 years old (median age 19 months $[9,0 ; 38,5]$ ) with $\mathrm{KD}$, among them, in 10 patients the disease was complicated by CAA formation according to echocardiography, and 30 children of the control group.

Results: Three out of six investigated SNPs showed statistically significant difference in genotype and allele distribution: CRP C3872T, CD14 C159T and FGB G455A. CRP gene polymorphism: in patients with KD significantly less frequent is homozygous type TT ( $R R$ 0,22, 95\% Cl: 0,05-0,91, p=0,0168).

CD14 gene polymorphism: in control group heterozygous genotype CT is predominant, ( $R R$ 0,58, 95\% Cl: 0,4-0,83, p=0,0017) among patients with $\mathrm{KD}$ homozygous genotypes CC and TT are predominant. (RR 3,61, 95\% Cl: 1,14$11,49, p=0,0057$ )

FGB gene polymorphism: genotype GA is predominant in control group (RR $0,48,95 \% \mathrm{Cl}: 0,26-0,9, \mathrm{p}=0,0149)$. In patients with $\mathrm{KD}$ significantly less frequent is homozygous type GG (RR 1,69, 95\% Cl: 1,03-2,8, $p=0,0297$ ).

We didn't find any significant difference in genotype and allele distribution in KD patients with and without CA lesions.

Conclusion: statistically significant differences $(p<0,05)$ were revealed in the distribution of genotypes for polymorphisms of the CD14 -159 C>T, CRP $3872 \mathrm{C}>\mathrm{T}$ and FGB $-455 \mathrm{G}>\mathrm{A}$ genes among patients with $\mathrm{KD}$ and children of the control group; when comparing the results of KD patients with CAA and the control group, statistically significant differences $(p<0,05)$ were revealed only in the polymorphism CD14 -159 C>T. It can be assumed that these polymorphisms are associated with the development of KD and CAA in these patients.

Disclosure of Interests: None declared

DOI: 10.1136/annrheumdis-2021-eular.2807

\section{AB0736 JUVENILE IDIOPATHIC ARTHRITIS IN ADULTHOOD: TRENDS OF THE DISEASE AND SOCIO- PROFESSIONAL FUTURE}

S. Miladi ${ }^{1}$, M. Yasmine ${ }^{1}$, S. Mariem ${ }^{1}$, A. Fazaa ${ }^{1}$, K. Ouenniche ${ }^{1}$, L. Souebni ${ }^{1}$, S. Kassab ${ }^{1}$, S. Chekili ${ }^{1}$, K. Ben Abdelghani ${ }^{1}$, A. Laatar ${ }^{1} .{ }^{1}$ Mongi Slim Hospital, Rheumatology, Tunis, Tunisia

Background: Juvenile idiopathic arthritis (JIA) is the most common arthropathy of childhood that may lead to physical disability and reduced quality of life, thus hindering the ability of the patients to achieve a meaningful adult life.

Objectives: The aim of this study was to assess the trends of the disease and socio-professional future.

Methods: We conducted a retrospective study including adult patients aged > 18 years with a history of JIA according to the International League of Associations for Rheumatology (ILAR). Collected data included age, sex, the 